\title{
PENGARUH HISTOGRAM EQUALIZATION UNTUK PERBAIKAN KUALITAS CITRA DIGITAL
}

\author{
Sisilia Daeng Bakka Mau \\ Fakultas Teknik, Program Studi Teknik Informatika \\ Universitas Katolik Widya Mandira Kupang \\ Email: sisilia901@gmail.com
}

\begin{abstract}
ABSTRAK
Penelitian ini membahas penggunaan metode histogram equalization yang akan digunakan untuk perbaikan kualitas citra. Perbaikan kualitas citra (image enhancement) merupakan salah satu proses awal dalam peningkatan mutu citra. Peningkatan mutu citra diperlukan karena seringkali citra yang dijadikan objek pembahasan mempunyai kualitas yang buruk, misalnya citra mengalami derau, kabur, citra terlalu gelap atau terang, citra kurang tajam dan sebagainya. Perbaikan kualitas citra adalah proses memperjelas dan mempertajam ciri atau fitur tertentu dari citra agar citra lebih mudah dipersepsi maupun dianalisa secara lebih teliti. Hasil penelitian ini membuktikan bahwa penggunaan metode histogram equalization dapat digunakan untuk meningkatkan kontras citra dan dapat meningkatkan kualitas citra, sehingga informasi yang ada pada citra lebih jelas terlihat.
\end{abstract}

Kata kunci: perbaikan kualitas citra, histogram equalization, citra digital.

\begin{abstract}
This study discusses the use histogram equalization method to be used for image quality improvement. Improvements to the quality image (image enhancement) is one of the initial process in improving the quality of the image. Improved image quality is needed because often the image that made the object of discussion has poor quality, for example, the image of experiencing noise, blurred, the image is too dark or too light, the image less sharp, and so on. Image quality improvement is the process of clarifying and sharpening characteristics or features of the image so that the image is more easily perceived and analyzed more thoroughly. The results of this study proved that the use histogram equalization method can be used to enhance the image contrast and can improve the quality of the image, so that the information contained in the image more clearly visible.
\end{abstract}

Keywords : image quality improvement, histogram equalization, digital image.

\section{PENDAHULUAN}

Citra (image) atau istilah lain untuk gambar sebagai salah satu komponen multimedia yang memegang peranan sangat penting sebagai bentuk informasi visual. Meskipun sebuah citra kaya akan informasi, namun sering kali citra yang dimiliki mengalami penurunan mutu, misalnya mengandung cacat atau noise. Tentu saja citra semacam ini menjadi lebih sulit untuk diinterpretasikan karena informasi yang disampaikan oleh citra tersebut menjadi berkurang.

Derau (noise) dalam pengolahan citra digital merupakan gangguan yang disebabkan oleh penyimpanngan data digital yang diterima oleh alat penerima data gambar. Alat penerima data gambar ini bisa berbentuk berbagai macam, mulai dari kamera analog maupun jenis kamera digital dan juga scanner.[1]

Sampai saat ini, banyak metode yang telah dicoba untuk mengurangi banyaknya derau pada citra digital dengan tujuan memperbaiki kualitas citra (Image Enhancement). Metode ini bertujuan untuk memperbaiki citra dengan cara manipulasi parameter-parameter citra sehingga ciri-ciri khusus dalam citra dapat ditonjolkan.

Salah satu teknik Image Enhancement yang digunakan adalah histogram citra. Histogram citra dikatakan baik bila mampu melibatkan semua level atau aras yang mungkin pada level ke-abu-an. Tentu saja tujuannya agar mampu menampilkan detil pada citra sehingga mudah untuk diamati. Penggunaan metode histogram equaliazation ini dianggap mudah karena karena kesederhanaan dan relatif lebih baik kinerja pada hampir semua jenis gambar. Metode histogram equalization sangat efektif digunakan tidak hanya dalam meningkatkan seluruh gambar tetapi juga dalam meningkatkan detail tekstur. Hal ini juga 
membuat perubahan urutan tingkat warna abu-abu gambar asli benar-benar terkendali. Dengan demikian dapat meningkatkan gambar lebih efektif.

Berdasarkan latar belakang tersebut, maka dapat didefinisikan masalah yang akan diangkat dalam penelitian ini adalah bagaimana mengimplementasikan histogram equalization untuk meningkatkan kualitas citra dan meningkatkan detail tekstur citra untuk mendapatkan hasil gambar yang lebih baik lagi.

Tujuan yang hendak dicapai dalam penelitian ini adalah mengimplementasikan histogram equalization untuk meningkatkan kualitas citra agar informasi yang ada pada citra terlihat lebih jelas. Penelitian ini diharapkan mampu menghasilkan sebuah solusi yang lebih efektif untuk perbaikan kualitas citra digital.

\section{METODOLOGI PENELITIAN}

Pemerataan histogram telah banyak diterapkan dan dikembangkan, multi-histogram equalization yang digunakan untuk meningkatkan kontras dan kecerahan citra. Histogram equalization dinamis dapat menghasilkan output gambar dengan intensitas gambar rata-rata sama dengan intensitas rata-rata gambar input. Tidak hanya saja pada gambar, metode histogram equalization juga dapat diterapkan pada video yang juga dapat menghasilkan output gambar yang cerah.

Penelitian yang dilakukan oleh Ahmad dengan menggunakan metode histogram equalization dapat meningkatkan kualitas citra sehingga informasi yang terdapat pada citra lebih jelas terlihat. Penggunaan metode histogram equalization ini dianggap mudah karena kesederhanaan dan relatif lebih baik kinerjanya pada hampir semua jenis gambar. Metode histogram equalization sangat efektif digunakan tidak hanya dalam meningkatkan seluruh gambar tetapi juga dalam meningkatkan detail tekstur. Hal ini juga membuat perubahan urutan tingkat warna abu-abu gambar asli benar-benar terkendali. Dengan demikian dapat meningkatkan gambar lebih efektif.[2]

Penelitian yang dilakukan Akhlis adalah mendesain sebuah perangkat lunak untuk meningkatkan kualitas citra digital foto roentgen yaitu dengan meningkatkan kontras citra dengan menggunakan metode histogram equalization. Dimana metode tersebut membuat tingkat keabuan citra tersebar merata pada semua tingkat keabuan citra sehingga dapat meningkatkan kontras citra.[3]

Perbaikan kualitas citra merupakan suatu proses yang dilakukan untuk mendapatkan kondisi tertentu pada citra. Proses tersebut dilakukan dengan menggunakan berbagai macam metode tergantung pada kondisi yang diharapkan pada citra, seperti mempertajam bagian tertentu pada citra, menghilangkan noise atau gangguan, manipulasi kontras dan skala keabuan, dan sebagainya.

Derau (Noise) adalah titik-titik pada citra yang sebenarnya bukan merupakan bagian dari citra, melainkan ikut tercampur pada citra karena suatu sebab. Noise muncul biasanya sebagai akibat dari pembelokkan yang tidak bagus (sensor noise, photographic gain noise). Gangguan tersebut umumnya berupa variasi intensitas suatu piksel yang tidak berkorelasi dengan piksel-piksel tetangganya. Secara visual, gangguan mudah dilihat oleh mata karena tampak berbeda dengan piksel tetangganya. Piksel yang mengalami gangguan umumnya memiliki frekuensi tinggi. Komponen citra yang berfrekuensi rendah umumnya mempunyai nilai piksel konstan atau berubah sangat lambat. Operasi denoise dilakukan untuk menekan komponen yang berfrekuensi tinggi dan meloloskan komponen yang berfrekuensi rendah.[4]

Adapun proses yang termasuk dalam image enhancement adalah : perubahan kecerahan gambar (image brightness), peregangan kontras (contrast stretching), perubahan histogram (histogram equalization), pelembutan citra (image smoothing), penajaman tepi (sharpening edge), pewarnaan semu (pseudocolouring), perubahan geometrik. Pada umumnya, peningkatan kualitas citra dilakukan melalui penggambaran histogram citra tersebut melalui metode histogram equalization. Metode ini bekerja dengan cara menggambarkan sebaran piksel-piksel dalam suatu histogram dengan mengubah nilai tingkat keabuan (gray level value) piksel-piksel tertentu tanpa memperhatikan lokasinya dalam image. Citra histogram adalah satu nilai yang memungkinkan untuk digunakan sebagai gambaran intensitas dari suatu citra.[4]

Menurut Munir, histogram citra adalah grafik yang menggambarkan penyebaran nilai-nilai intensitas piksel dari suatu citra. Dari sebuah histogram dapat diketahui frekuensi kemunculan nisbi (relative) citra tersebut. Histogram juga dapat menunjukkan banyak hal tentang kecerahan (brightness) dan kontras (contrast) dari sebuah citra. Secara matematis histogram citra dihitung dengan persamaan :

$\mathrm{hi}=\frac{\mathrm{ni}}{n}, i=0,1_{s \ldots x} L-1$

dengan $\mathrm{n}=$ jumlah seluruh piksel di dalam citra dan $\mathrm{ni}=$ jumlah piksel yang memiliki derajat keabuan i. Distribusi hi, atau ni, dapat menyediakan informasi tentang kemunculan citra. Pengetahuan praktis untuk memahami histogram citra dibutuhkan untuk melihat perubahan-perubahan pada citra 
setelah dilakukan operasi tertentu. Beberapa pengetahuan praktis yang biasa digunakan dalam melihat histogram citra adalah sebagai berikut:

a. Histogram citra yang terdistribusi merata pada seluruh tingkat keabuan memiliki kontras yang baik.

b. Histogram citra yang mengumpul pada daerah gelap memiliki citra yang redup.

c. Histogram citra yang mengumpul pada daerah terang atau terkonsentrasi pada intensitas citra yang tinggi menampilkan citra yang terang.

Disamping itu dalam upaya menampakkan informasi sebanyak mungkin pada citra maka histogram dibuat semerata mungkin yang disebut dengan penyamaan histogram (histogram equalization). Tujuan ekualisasi histogram adalah untuk memperoleh penyebaran histogram yang merata, sehingga setiap derajat keabuan memiliki jumlah piksel yang relatif sama.

Yang dimaksud dengan perataan histogram adalah mengubah derajat keabuan suatu piksel (r) dengan derajat keabuan yang baru (s) dengan suatu fungsi transformasi $\mathrm{T}$, yang dalam hal ini $\mathrm{s}=\mathrm{T}(\mathrm{r})$. Dua sifat yang dipertahankan pada transformasi ini adalah :

a. Nilai s merupakan pemetaan 1 ke 1 dari r. Ini untuk menjamin representasi intensitas yang tetap. Ini berarti $r$ dapat diperoleh kembali dari $r$ dengan transformasi invers: $r=T-1(s), 0 \leq s \leq 1$

b. Untuk $0 \leq \mathrm{r}_{\mathrm{i}} \leq 1$, maka $0 \leq \mathrm{T}(\mathrm{r}) \leq 1$. Ini untuk menjamin pemetaan $\mathrm{T}$ konsisten pada rentang nilai yang diperbolehkan.[5]

Pada penelitian untuk pengembangan aplikasi perbaikan citra digital dilakukan beberapa tahapan sebagai berikut :

a. Menentukan suatu citra digital yang digunakan sebagai sampel untuk obyek penelitian.

b. Pembuatan aplikasi atau software dengan MATLAB 7.

c. Dalam program aplikasi dilakukan beberapa langkah pengolahan citra digital sebagai berikut:

1) Pengambilan citra digital dari suatu file digital

2) Perbaikan intensitas citra digital

3) Peredaman derau dengan menggunakan histogram equalization

4) Penyimpanan citra hasil pengolahan kedalam file

\section{HASIL PENELITIAN DAN PEMBAHASAN}

Peningkatan citra adalah salah satu bagian yang sangat penting dalam pengolahan citra tingkat rendah. Tujuannya adalah untuk meningkatkan kualitas gambar yang memiliki nilai kontras yang rendah, untuk memperbesar perbedaan intensitas antara objek-objek dan latar belakang gambar dan meningkatkan interpretability atau persepsi informasi yang terdapat pada gambar. Dari banyaknya teknik image enhancement, dalam penelitian ini akan digunakan metode histogram equalization. Tujuan ekualisasi histogram adalah untuk memperoleh penyebaran histogram yang merata, sehingga setiap derajat keabuan memiliki jumlah piksel yang relatif sama.

Berikut adalah flowchart yang digunakan dalam proses perbaikan citra :

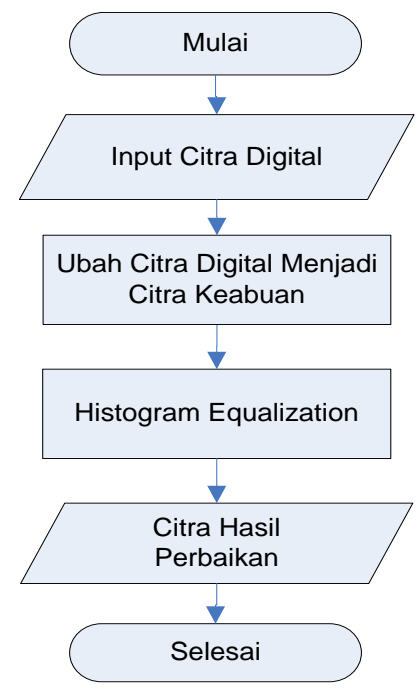

\section{Gambar 1. Flowchart Perbaikan Kualitas Citra Digital}

Dari gambar 1 diatas dapat dilihat bahwa proses dimulai saat menginput citra digital. Citra digital akan diubah dalam bentuk citra keabuan. Setelah itu akan dilakukan proses histogram equalization untuk 
memperoleh penyebaran histogram yang merata sehingga setiap derajat intensitas warna memiliki jumlah piksel yang relatif sama. Karena histogram menyatukan peluang piksel dengan derajat keabuan tertentu, maka rumus menghitung histogram ditulis kembali sebagai peluang :

$P_{\mathrm{r}}\left(\mathrm{r}_{\mathrm{k}}\right)=\frac{\mathrm{n}_{\mathrm{k}}}{\mathrm{n}}$

Yang dalam hal ini,

$n_{k}=\frac{k}{L-1} \ldots, 0 \leq n_{k} \geq 1$

Dengan mengubah derajat keabuan suatu piksel (r) menjadi derajat keabuan yang baru (s) dengan suatu fungsi transformasi $\mathrm{T}$ yang dalam hal ini $\mathrm{s}=\mathrm{T}(\mathrm{r})$, maka untuk perataan histogram digunakan rumus :

$s_{k}=T\left(n_{k}\right)=\sum_{j=0}^{k} \frac{n_{j}^{j}}{n}=\sum_{j=0}^{k} P_{r}\left(r_{j}\right)$

Berdasarkan flowchart yang dijelaskan pada gambar 1, maka berikut adalah implementasi yang dibuat dengan menggunakan program Matlab 7.

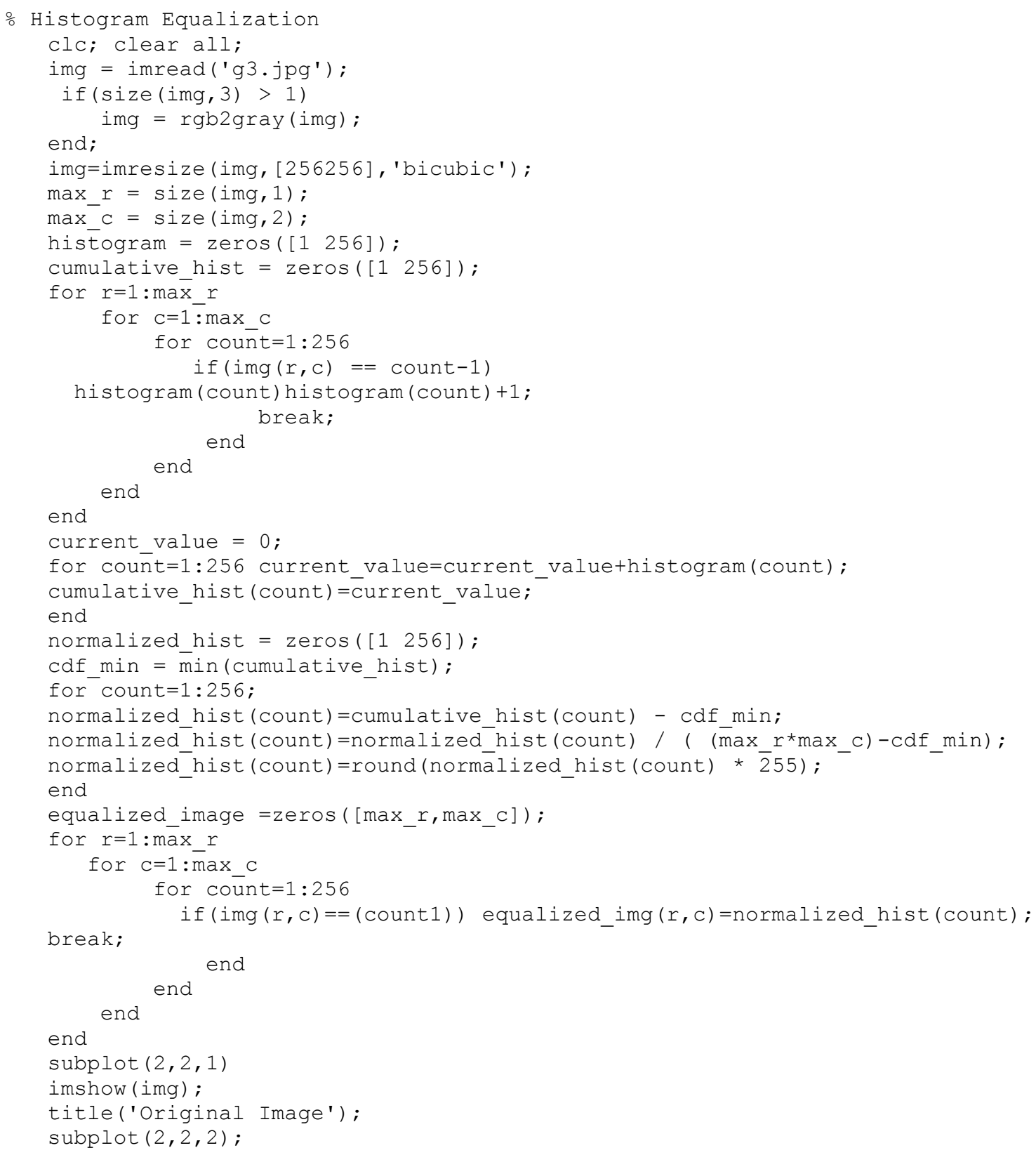




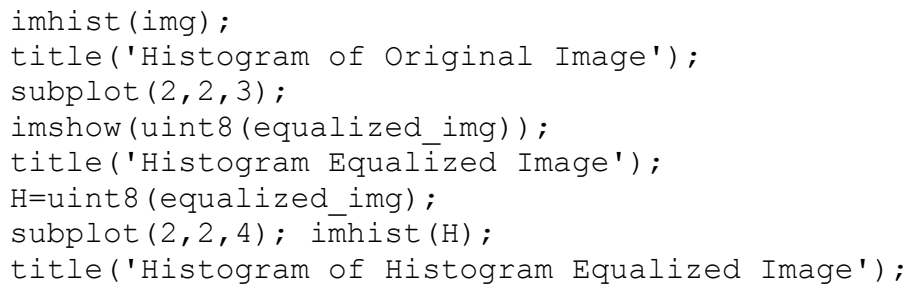

Berikut adalah tampilan hasil runing program di atas :

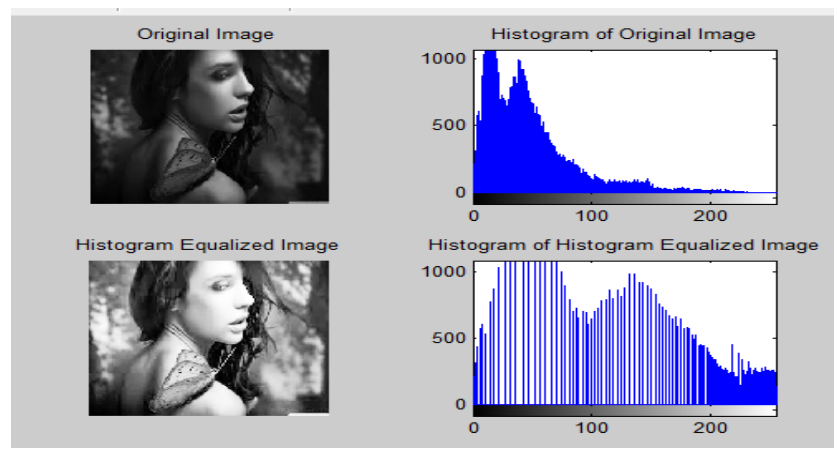

Gambar 2. Hasil Perbaikan Citra 1

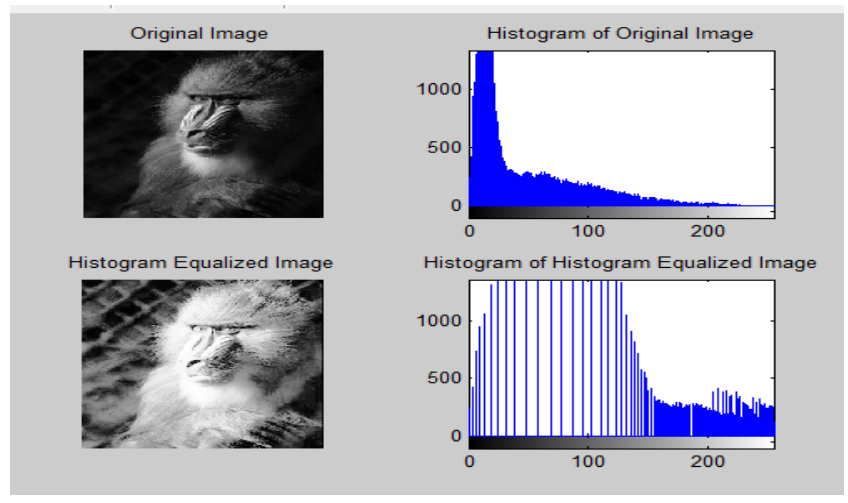

Gambar 3. Hasil Perbaikan Citra 2

Dari gambar 2 dan gambar 3 diatas, bisa dilihat bahwa citra output hasil persebaran histogramnya jauh lebih merata dibanding citra input. Dengan demikian histogram yang lebih merata maka akan meningkatkan persebaran nilai grayscale sehingga citra output akan terkesan terlihat lebih terang dan detailnya lebih terlihat.

\section{KESIMPULAN}

Berdasarkan hasil penelitian, dapat disimpulkan bahwa dari hasil uji coba yang telah dilakukan dengan menggunakan 2 buah citra digital sebagai perbandingan menunjukkan bahwa metode histogram equalization dapat digunakan untuk meningkatkan kontras citra dan kualitas citra, sehingga informasi yang ada pada citra yang telah diperbaiki akan terlihat lebih jelas dibandingkan dengan citra asli sebelum diperbaiki.

\section{DAFTAR PUSTAKA}

[1] Sulistyo, T. (2009). Teori Pengolahan Citra Digital. Yogyakarta : Penerbit Andi.

[2] Ahmad, N,.and Hadinegoro, A. 2012. "Metode Histogram Equalization Untuk Perbaikan Citra Digital”. Seminar Nasional Teknologi Informasi \& Komunikasi Terapan 2012 (Semantik 2012) ISBN 979 - 26 - $0255-0$.

[3] Akhlis, I. S. 2011. "Implementasi Metode Histogram Equalization Untuk Meningkatkan Kualitas Citra Digital". Jurnal Fisika Vol. I No. 2. 
[4] Murinto, et al., 2008. "Analisis Perbandingan Histogram Equalization dan Mndel Logarithmic Image Processing Untuk Image Enhancement". Jurnal Informatika Vol 2. No. 2.

[5] Munir, R. (2004). Pengolahan Citra Digital dengan Pendekatan Logaritmik. Bandung : Penerbit Informatika. 